\title{
Analisis Struktur Bangunan Gedung Sekolah akibat Penambahan Ruang Kelas Baru (Studi Kasus di SMK Bina Putera Kota Bogor)
}

\author{
Structural Analysis of School Building due to New Classrooms \\ Addition (Case Study of SMK Bina Putera Bogor City)
}

\author{
Agung Prabowo ${ }^{1, a)}$ \& Muhamad Lutfi ${ }^{1, b)}$ \\ ${ }^{1}$ )Program Studi Teknik Sipil, Fakultas Teknik dan Sains, Universitas Ibn Khaldun, Bogor \\ Koresponden : ${ }^{a)}$ prabowoa3@gmail.com \& ${ }^{b}$ lutfim97@gmail.com
}

\begin{abstract}
ABSTRAK
Penelitian dilakukan pada gedung Sekolah Menengah Kejuruan Bina Putera yang memiliki luas tanah $1172 \mathrm{~m}^{2}$. Pada tahun 2017 sampai 2019 terdapat kenaikan jumlah siswa sebesar 55,7 \%, sehingga perlu penambahan ruang kelas baru. Dimana luas lahan sudah tidak dapat digunakan untuk membangun ruang kelas secara horizontal, maka sekolah menambah ruang kelas secara vertikal pada bangunan 2 lantai menjadi 3 lantai. Penelitian dilakukan dengan pengujian mutu beton menggunakan Hammer Test didapatkan hasil 20,75 MPa, kemudian dilakukan permodelan analisis menggunakan software Etabs V9.5.0 dan perhitungan manual berdasarkan SNI 03-2847-2002, SNI 031726-2012, dan SNI 1729-2015. Pada analisis ini dibuat 3 tahap, pertama kondisi awal pada bangunan eksisting, kedua analisis struktur eksisting dengan beban tambahan ruang kelas baru, dan ketiga analisis dengan beban tambahan dan perkuatan struktur. Hasil analisis struktur tahap 1 dan 2 menyatakan elemen struktur balok mengalami over strengh $(\mathrm{O} / \mathrm{S})$ atau tidak dapat menahan beban tambahan ruang kelas baru. Dengan adanya data tersebut maka dilakukan perhitungan perkuatan struktur menggunakan metode concret jacketing dengan tebal $10 \mathrm{~cm}$ dan jumlah tulangan longitudinal 5D16 sengkang Ø8-100 serta metode perkuatan dengan profil baja WF 200.200.8.12. Estimasi biaya perkuatan concrete jacketing lebih mahal dari perkuatan profil baja dengan selisih harga $\mathrm{Rp}$ 11.771.225,00 atau $81 \%$.
\end{abstract}

Kata Kunci : manajemen infrastruktur, struktur, gedung sekolah, hammer test, Etabs V9.5.0

\section{PENDAHULUAN}

Infrastruktur pendidikan seperti gedung sekolah merupakan infrastruktur vital yang harus dikelola dengan baik. Gedung sekolah harus dikelola dengan baik sesuai dengan prinsip Manajemen Aset Infrastruktur \& Fasilitas (Suprayitno \& Soemitro, 2018). Kadang-kadang gedung sekolah harus dikembangkan karena kapasitas yang ada tidak memadai lagi. Perancangan pengembangan struktur harus dilakukan dengan baik.

Sekolah Bina Putera Kota Bogor memiliki luas tanah $1172 \mathrm{~m}^{2}$ terbagi atas 2 jenjang sekolah yaitu SMP Bina Putera Bogor dan SMK Bina Putera bogor dengan jumlah bangunan sebanyak 19 ruang kelas terbagi atas 11 ruang kelas SMP dan 8 ruang kelas SMK dan fasilitas pelengkap. Jumlah siswa SMK pada tahun 2017 berjumlah 298 siswa dan tahun 2019 berjumlah 464 siswa, telah terjadi kenaikan jumlah siswa sebesar 55,7 \% dari tahun 2017 ke 2019. Dengan luas lahan yang sudah tidak dapat digunakan untuk membangun ruang kelas secara horizontal, maka sekolah menambah 4 ruang kela133s secara vertikal pada gedung sekolah yang terdiri 
dari 2 lantai dan 4 ruang setiap lantainya, menjadi 3 lantai dengan jumlah total 12 ruang kelas pada gedung tersebut. Berdasarkan hal tersebut, diperlukan kajian struktur eksisting untuk mengetahui apakah struktur bangunan yang sudah ada dapat menahan beban berupa penambahan lantai ruang kelas baru. Menentukan metode yang perlu dilakukan untuk menahan beban lantai kelas baru jika bangunan eksisting tidak mampu menahan beban tambahan.

Penelitian ini di batasi oleh beberapa ketentuan diantaranya dua hal berikut ini. Analisa struktur mencakup struktur bangian atas, tidak melakukan analisa terhadap struktur bangian bawah/fondasi. Analisis struktur menggunakan bantuan Software Etabs V9.5.0 menurut peraturan pembebanan SNI 03-2847-2002, SNI 03-1726-2012, SNI 1729:2015.

\section{TINJAUAN PUSTAKA}

Infrastruktur adalah segala jenis struktur buatan manusia yang diperlukan untuk kehidupan publik dan kehidupan pribadi (Suprayitno \& Soemitro, 2018). Dalam bidang pendidikan, sekolah merupakan infrastruktur yang bermanfaat sebagai perantara dalam mencapai kesuksesan sebuah negara, agar manfaatnya tercapai maka pengelolaan infrastruktur harus dilakukan dengan baik.

Pedoman perhitungan struktur beton di Indonesia, telah diatur dalam Standar Nasional Indonesia dan perundang - undangan, adapun standar yang digunakan dalam analisis ini sebagai berikut :

1. SNI 03-2847-2002 tentang Tata Cara Perhitungan Struktur Beton Untuk Bangunan Gedung.

2. SNI 03-1726-2012, Tata Cara Perencanaan Ketahanan Gempa Untuk Bangunan Gedung UU No. 28 Tahun 2002. Undang-Undang Tentang Bangunan Gedung. Jakarta.

3. SNI 1729:2015, Spesifikasi untuk Bangunan Gedung Baja Struktural.

Dalam analisis struktur eksisting terhadap beban tambahan ruang kelas baru, terdapat beberapa parameter yang digunakan menurut Asroni (2010), diantaranya :

1. $\mathrm{Rr} \geq \mathrm{Ru}$

Kuat rencana $\mathrm{Rr}$ merupakan kekuatan gaya dalam (berada didalam struktur), sedangkan kuat perlu Ru merupakan kekuatan gaya luar (di luar struktur), yang bekerja pada struktur, maka kuar rencana $\mathrm{Rr}$ harus lebih besar dari kuat perlu $\mathrm{Ru}$.

Keterangan :

$\mathrm{Rr}$ : Kuat rencana

$\mathrm{Ru}$ : Kuat perlu

2. $\varnothing \mathrm{Mn} \geq \mathrm{Mu}$

Keterangan :

$\varnothing \quad$ : Faktor Reduksi

Mn : Momen Nominal

$\mathrm{Mu}:$ Momen Ultimit

3. $\varnothing \mathrm{Vn} \geq \mathrm{Vu}$

Keterangan :

$\varnothing \quad$ : Faktor Reduksi

$\mathrm{Vn}$ : Momen Nominal

$\mathrm{Vu}$ : Momen Ultimit

4. Tahanan balok desain LRFD menurut Setiawan (2013) harus memenuhi persyaratan :

$\varnothing$ b.Mn $>\mathrm{Mu}$

Keterangan :

$\varnothing \mathrm{b}: 0,90$

$\mathrm{Mn}$ : tahanan momen nominal

$\mathrm{Mu}:$ momen lentur akibat beban terfaktor 

berikut :

Dalam perencanaan perhitungan perkuatan concrete jacketing digunakan rumus sebagai

1. $\mathrm{Mn}=\frac{\mathrm{Mu}}{\phi}$ (n.mm)

Keterangan :

$\varnothing \quad$ : Faktor reduksi $(0,80)$

Mn : tahanan momen nominal

$\mathrm{Mu}:$ momen lentur akibat beban terfaktor (di dapat dari output analisis Etabs V9.50)

2. $\mathrm{Vn}=\frac{\mathrm{Vu}}{\phi}(\mathrm{kN})$

Keterangan :

$\varnothing \quad$ : Faktor Reduksi $(0,80)$

$\mathrm{Vn}$ : Momen Nominal

$\mathrm{Vu}$ : Momen Ultimit (nilai di dapat dari output analisis Etabs V9.50)

3. Balok terkekang lateral

$\mathrm{qu}=1,2 \mathrm{D}_{\mathrm{L}}+1,6 \mathrm{~L}_{\mathrm{L}}$

$\mathrm{Mu}_{\mathrm{U}}=\frac{1}{8} \times \mathrm{qu} \times \mathrm{L}^{2}$

$\mathrm{Mn}=\frac{\mathrm{Mu}}{\phi \mathrm{b}}$

Keterangan :

qu : beban terfaktor

$\varnothing \mathrm{b}: 0,90$

Mn : tahanan momen nominal

$\mathrm{Mu}:$ momen lentur akibat beban terfaktor

Penelitian yang dilakukan oleh Aswin (2019) menyatakan Over strength factor merupakan nilai kekuatan lebih yang dihasilkan oleh elemen struktur beton bertulang akibat tercapainya kapasitas ultimit penampang yang dibandingkan terhadap kapasitas penampang saat leleh / sudah tercapainya kapasitas ultimit yang dibutuhkan.

\section{METODOLOGI PENELITIAN}

Penelitian ini dilaksanakan pada bangunan Sekolah Menengah Kejuruan Bina Putera yang beralamat di jalan Pengairan Katulampa RT 01/RW 09, Katulampa, Kecamatan. Bogor Timur Kota Bogor, Jawa Barat. Waktu penelitian dari bulan November 2019 sampai bulan Januari 2020. Pengumpulan data yang digunakan dalam kegiatan ini berupa data primer (hasil uji hammer test dan pengukuran dimensi struktur bangunan) dan data sekunder (literatur mengenai struktur bangunan seperti SNI 03-2847-2002 tentang Tata Cara Perhitungan Struktur Beton untuk Bangunan Gedung).

Analisis dilakukan dengan menggunakan Software Etabs V9.5.0, dalam analisi ini dilakukan secara 3 tahap, yaitu :

1. Analisis struktur dengan mengevaluasi struktur gedung eksisting.

2. Analisis struktur eksting dengan beban tambahan ruang kelas baru.

3. Analisis dengan beban tambahan dan perkuatan struktur.

Dari hasil analisis tahap 1 dan 2 akan didapatkan output berupa kondisi elemen struktur yang mengalami kegagalan atau over strength $(\mathrm{O} / \mathrm{S})$ di tandai dengan warna merah pada elemen strukturnya, kemudian dilakukan analisa perkuatan dengan metode concrete jacketing dan perkuatan profil baja, pada tahap 3 dilakukan analisis modeling untuk mengetahui efek yang terjadi setelah dilakukan perkuatan. 


\section{HASIL DAN PEMBAHASAN}

\section{Analisis Struktur Eksisting}

Hasil kajian secara langsung dengan mengumpulkan informasi tentang struktur eksisting dapat dilihat pada Gambar 1 - 7, dengan data-data sebagai berikut :

$\begin{array}{ll}\text { Fungsi bangunan } & =\text { Bangunan sekolah } \\ \text { Jumlah lanta } & =2 \text { Lantai } \\ \text { Notasi lantai } & =\text { Lantai } 1 \text { diberi notasi Base } \\ & =\text { Lantai } 2 \text { diberi notasi Strory } 1 \\ \text { Kolom } & =\mathrm{K} 30 \times 30 \mathrm{~cm} \\ \text { Balok } & =\text { BL } 35 \times 25 \mathrm{~cm} \text { dan BL } 30 \times 20 \mathrm{~cm} \\ \text { Tebal pelat lantai } 2 & =120 \mathrm{~mm} \\ \text { Mutu beton kolom, balok dan pelat } & =\mathrm{K}-250(\mathrm{fc}=20,75 \mathrm{Mpa}) \\ \text { Modulus Elastisitas } & =21409,52 \\ \text { Berat Jenis beton bertulang } & =2400 \mathrm{~kg} / \mathrm{m}^{3} \\ \text { Mutu beton di dapat dari hasil pengujian menggunakan Hammer Test } & =\text { Fy } 390 \mathrm{Mpa}(\text { BJTD } 400) \\ \text { Mutu Baja } & =\text { Fy } 240 \mathrm{Mpa}(\text { BJTP 240) } \\ & =7833 \mathrm{~kg} / \mathrm{cm}^{3}\end{array}$

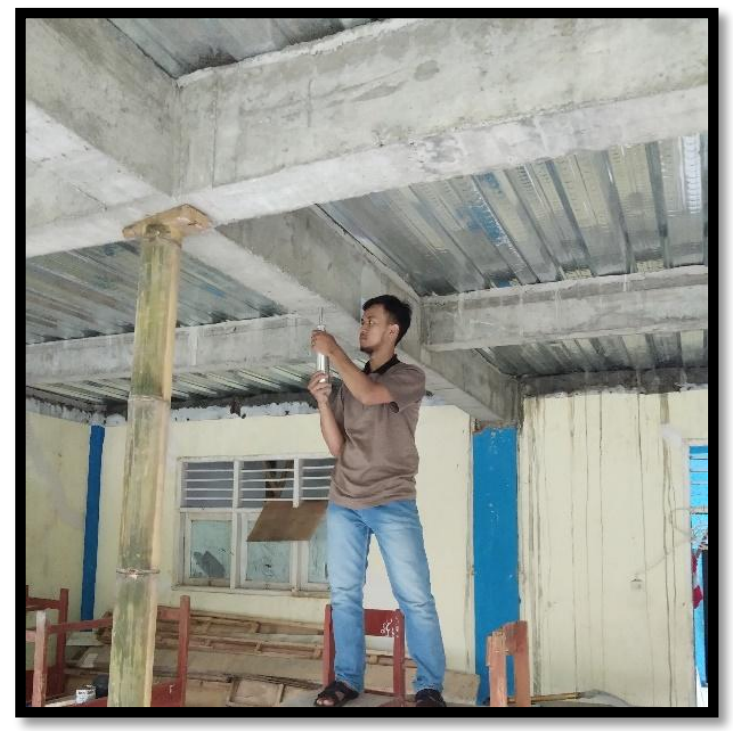

Gambar 1. Pengujian Hammer Test 


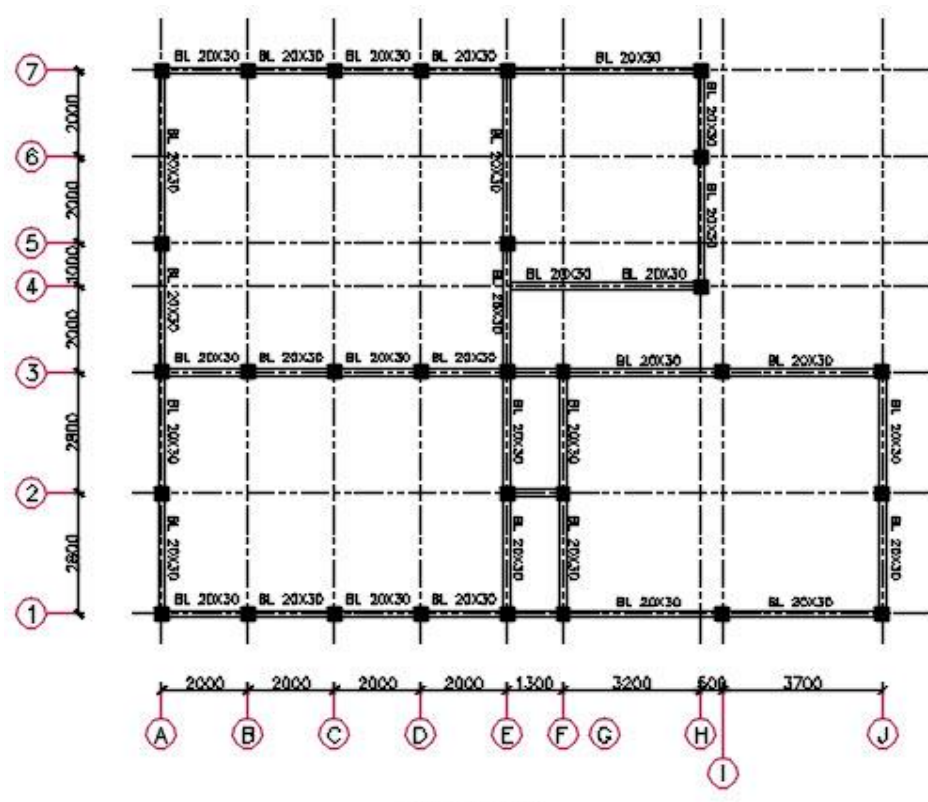

$\frac{\text { Denah Sloff }}{\text { Sklato } 1: \text { NTS }}$

(Sumber : Gambar dokumen pribadi)

Gambar 2. Denah Sloof

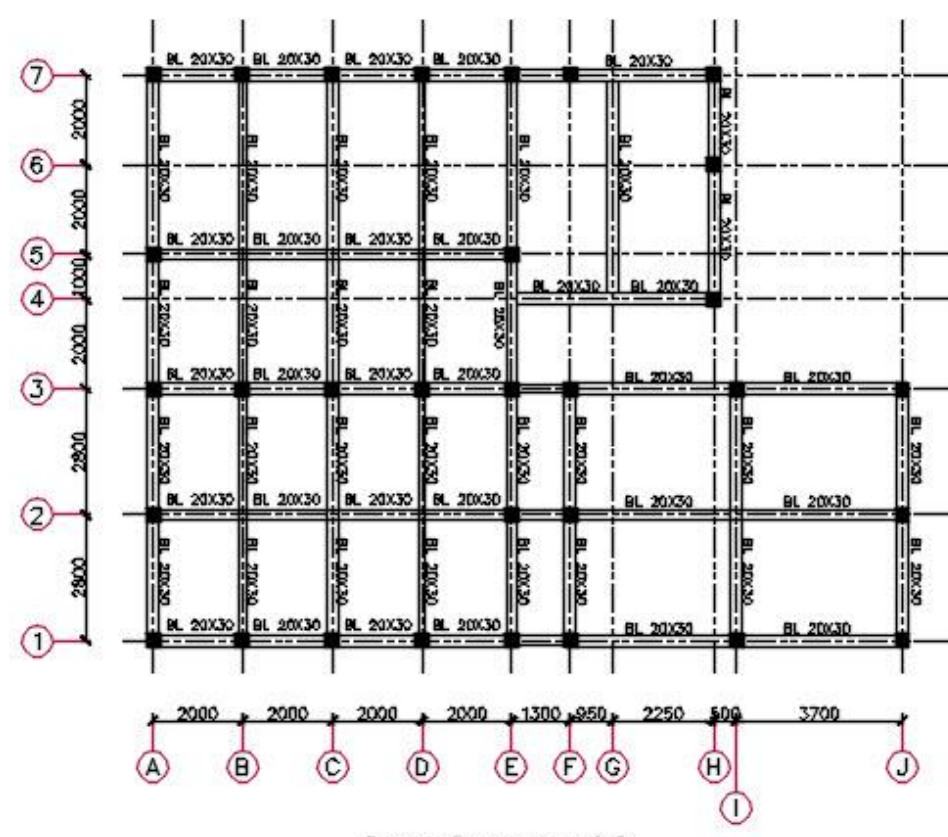

$\frac{\text { Denah Balok Lantai } 2}{\text { Skala 1:NTS }}$

(Sumber : Gambar dokumen pribadi)

Gambar 3. Denah Balok Lantai 2 


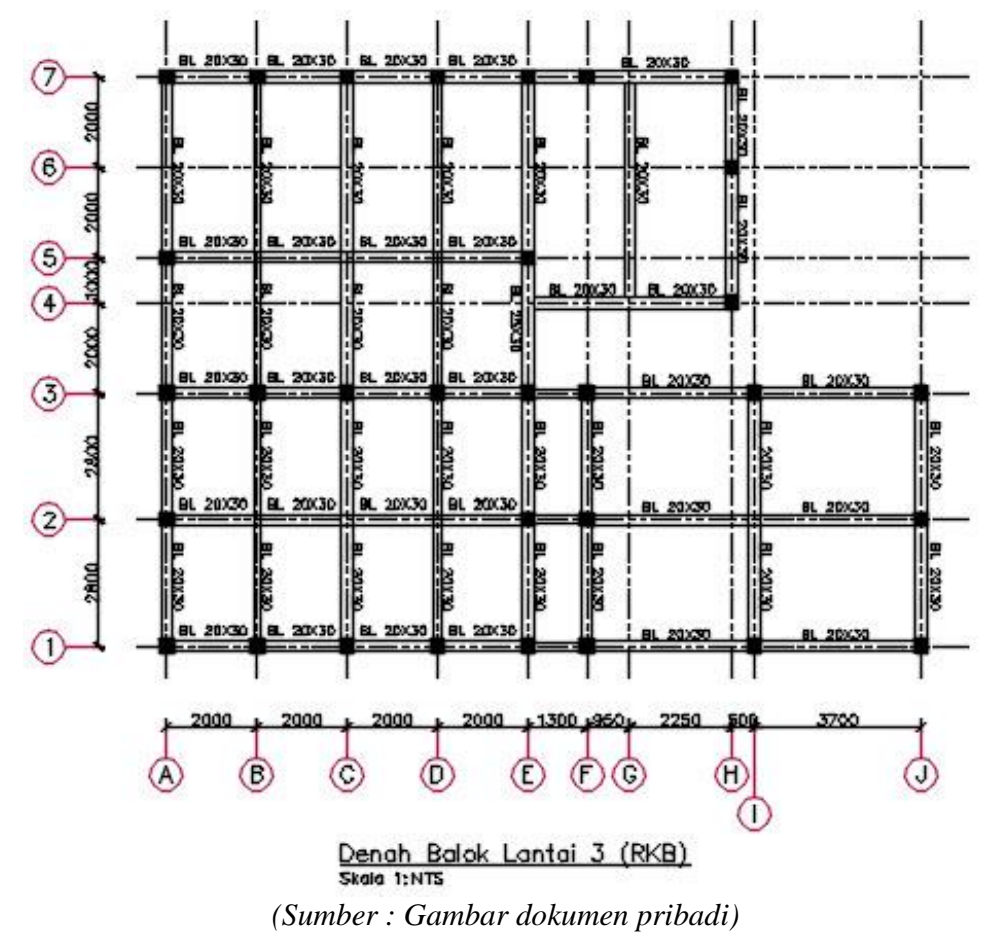

Gambar 4. Denah Balok Lantai 3 (ruang kelas baru)

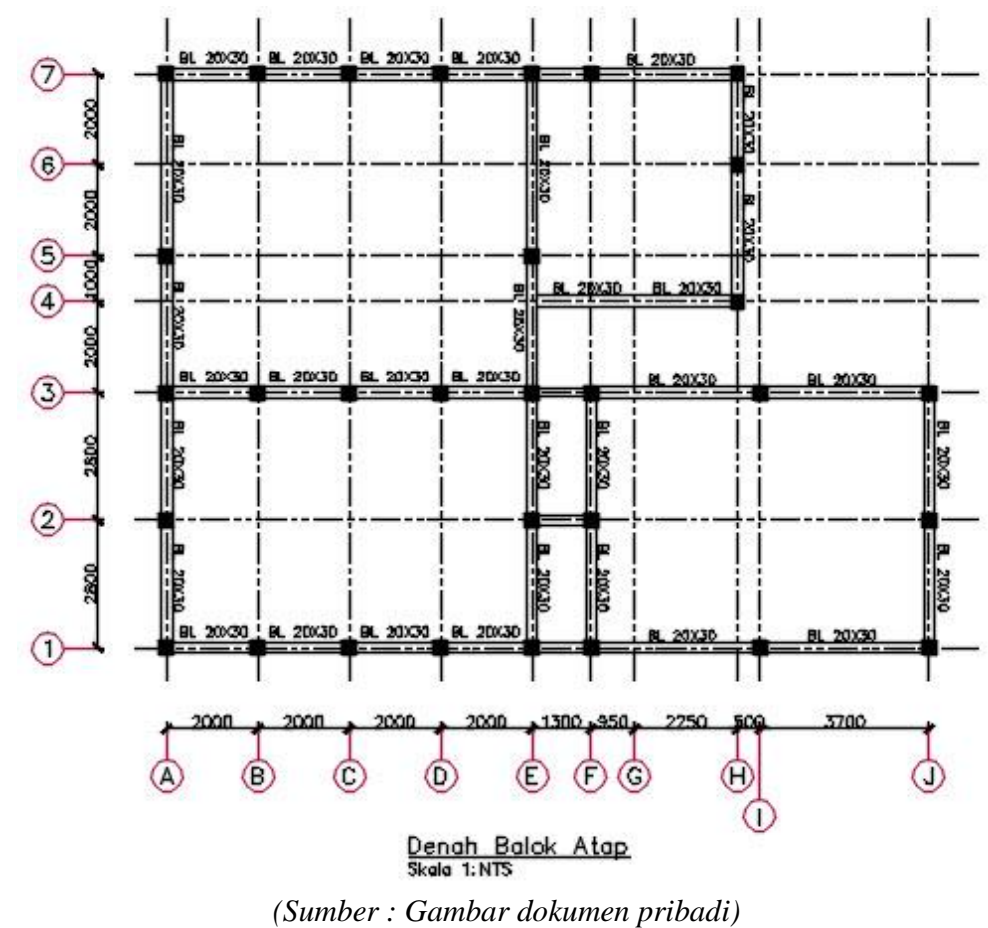

Gambar 5. Denah Balok Atap 

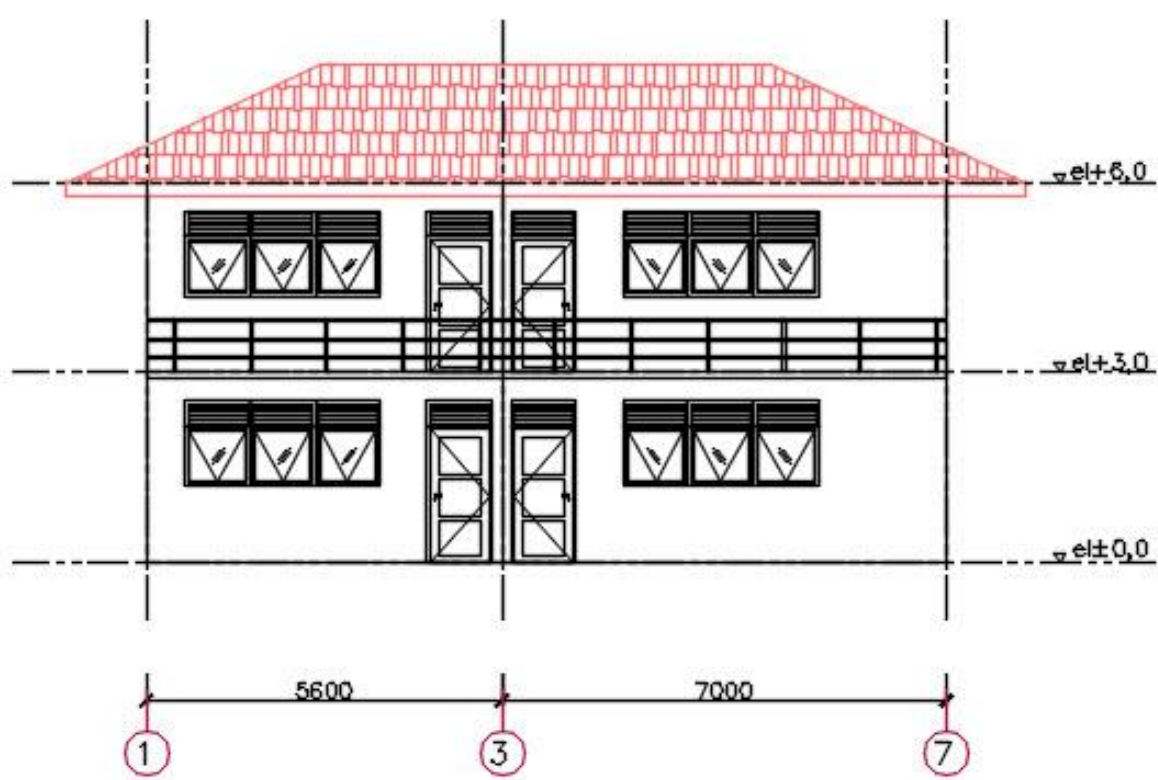

Tampak Depan

Skala 1: NTS

(Sumber : Gambar dokumen pribadi)

Gambar 6. Tampak Depan (Eksisting)

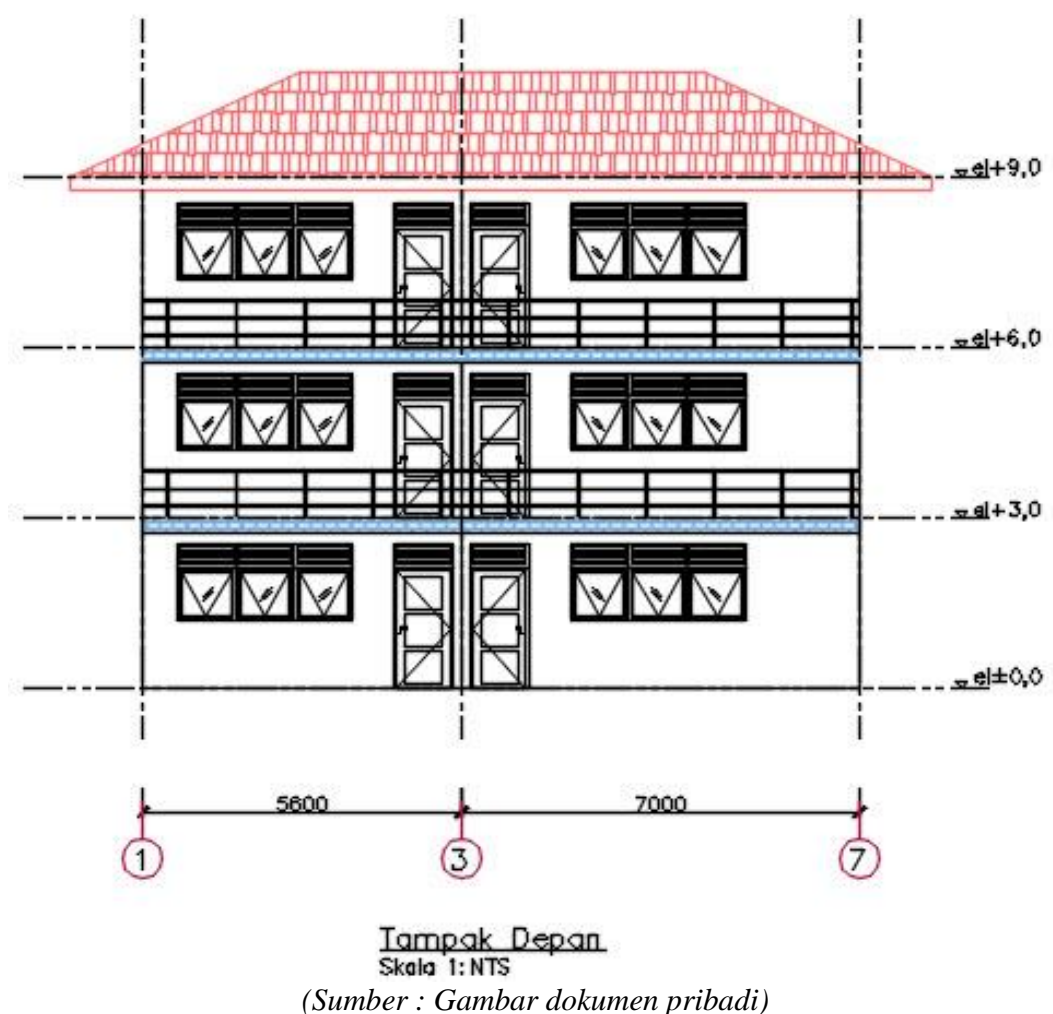

Gambar 7. Tampak Depan (Setelah dilakukan penambahan ruang kelas baru) 


\section{Analisis Tahap 1}

Berdasarkan data eksisting yang di dapat kemudian dilakukan permodelan 1 dengan Software Etabs V9.5.0

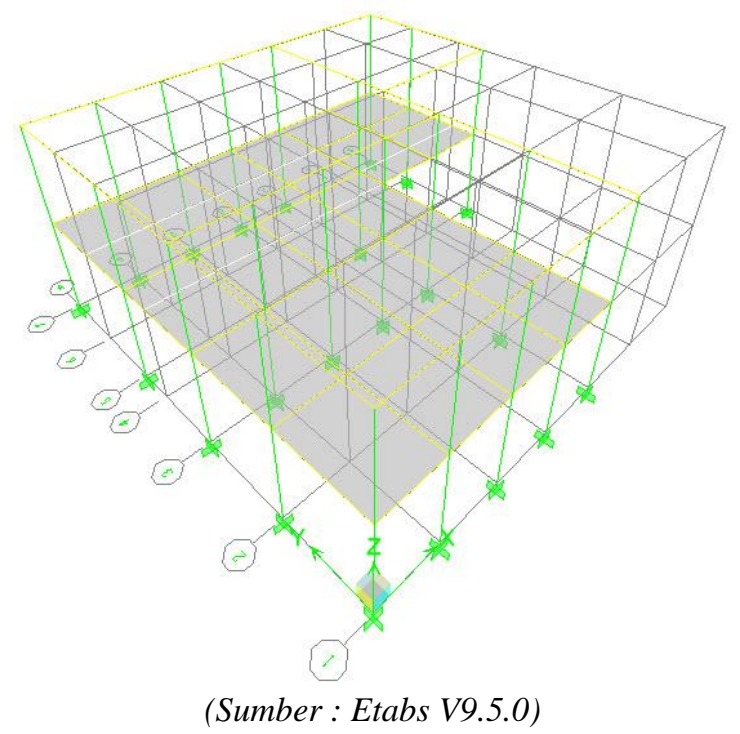

Gambar 8. Permodelan Struktur Eksisting

\section{Beban Mati dan Beban Hidup}

Analisis dilakukan dengan mamasukan data pembebanan, beban mati maupun beban hidup yang bekerja pada struktur bangunan dapat dilihat pada Tabel 1.

Tabel 1. Beban Mati dan Beban Hidup

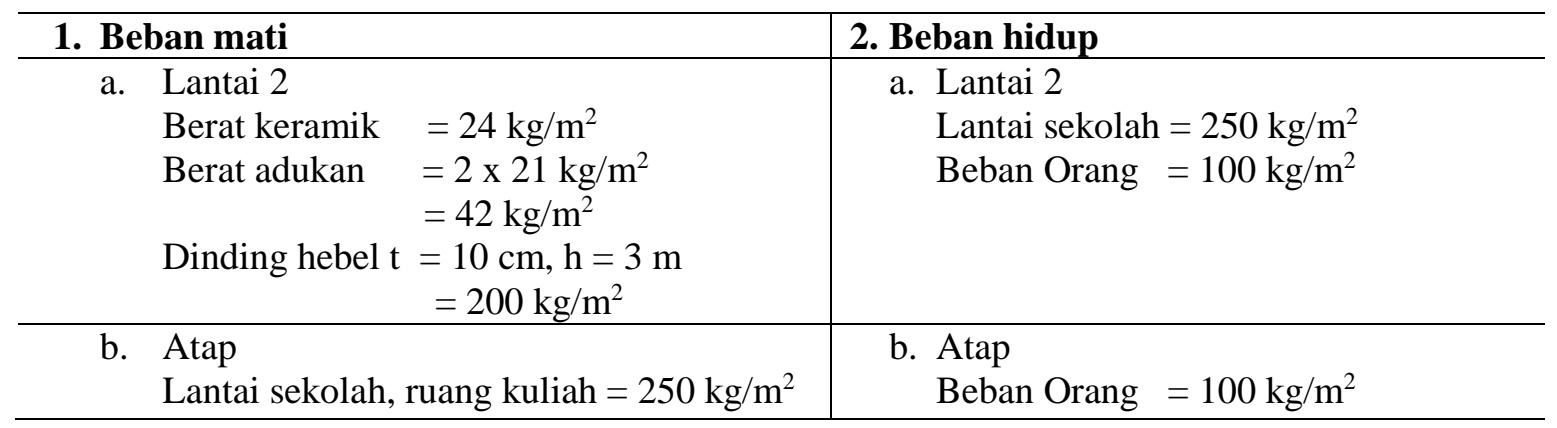

\section{Beban Gempa}

Besar beban gempa ditentukan oleh percepatan gempa rencana dan massa total struktur. Massa total struktur terdiri dari berat sendiri elemen struktur, beban mati dan beban hidup yang dikalikan faktor reduksi 0,8. Percepatan gempa diambil dari data zona 4 peta wilayah gempa (SNI 03-1726-2012) ditunjukan pada Gambar 9, kurva spectrum gempa rencana yang diambil sesuai dengan lokasi penelitian ditunjukkan pada Gambar 10. 

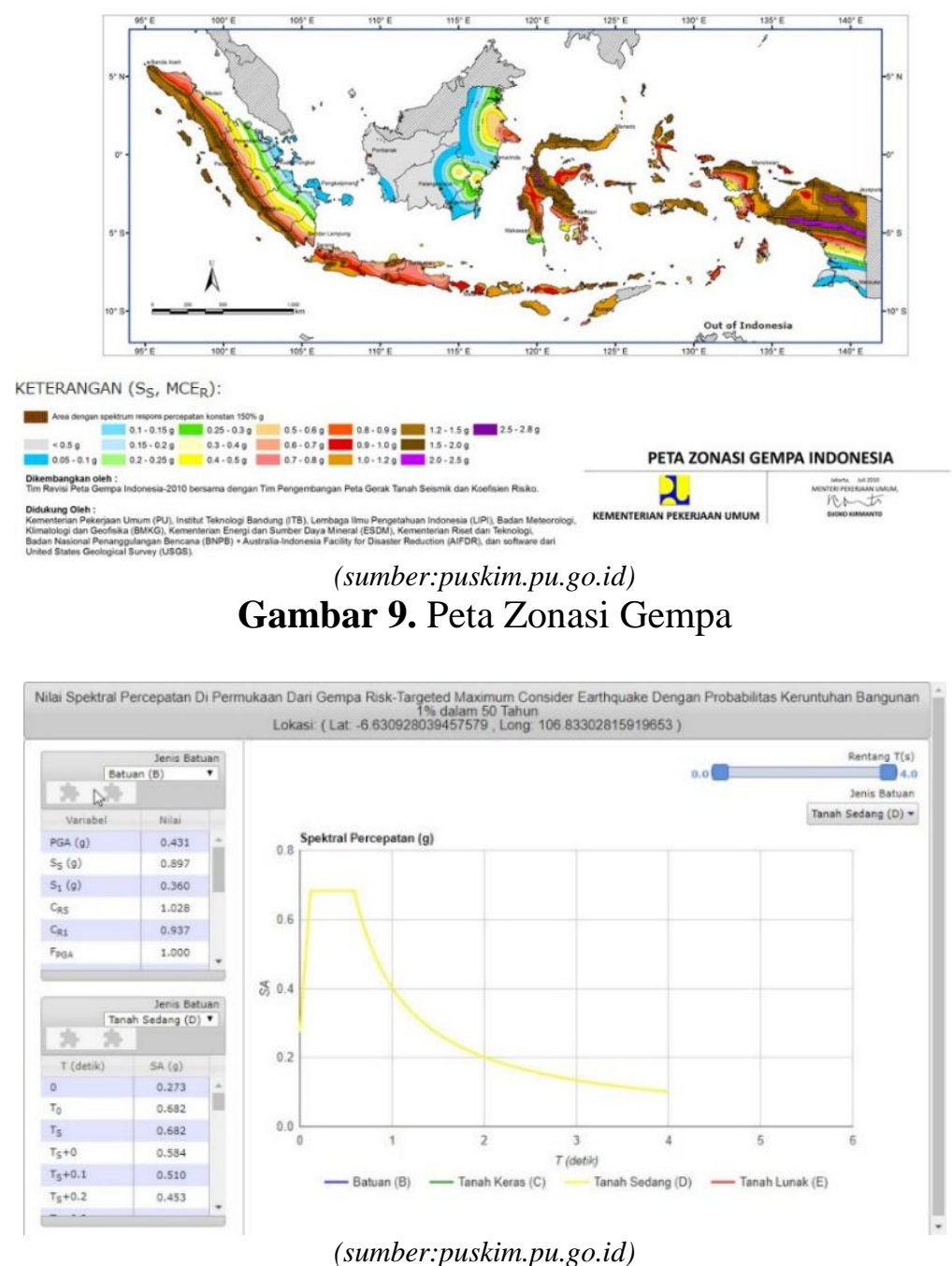

Gambar 10. Kurva Spectrum Gempa Rencana

\section{Kombinasi Pembebanan}

Kuat perlu adalah kekuatan minimal struktur yang diperlukan agar dapat menahan kombinasi beban mati, beban hidup dan beban gempa. Kuat perlu harus dihitung dengan ketentuan persamaan sebagai berikut:

Tabel 2. Kombinasi Pembebanan

\begin{tabular}{ll|ll}
\hline 1 & $\mathrm{U}=1,4 \mathrm{DL}$ & 8 & $\mathrm{U}=0,9 \mathrm{DL}+1,0 \mathrm{Fx}-0,3 \mathrm{Fy}$ \\
2 & $\mathrm{U}=1,2 \mathrm{DL}+1,6 \mathrm{LL}$ & 9 & $\mathrm{U}=0,9 \mathrm{DL}-1,0 \mathrm{Fx}+0,3 \mathrm{Fy}$ \\
3 & $\mathrm{U}=1,2 \mathrm{DL}+1,0 \mathrm{LL}+1,0 \mathrm{Fx}+0,3 \mathrm{Fy}$ & 10 & $\mathrm{U}=0,9 \mathrm{DL}-1,0 \mathrm{Fx}-0,3 \mathrm{Fy}$ \\
4 & $\mathrm{U}=1,2 \mathrm{DL}+1,0 \mathrm{LL}+1,0 \mathrm{Fx}-0,3 \mathrm{Fy}$ & 11 & $\mathrm{U}=1,2 \mathrm{DL}+1,0 \mathrm{LL}+0,3 \mathrm{Fx}+1,0 \mathrm{Fy}$ \\
5 & $\mathrm{U}=1,2 \mathrm{DL}+1,0 \mathrm{LL}-1,0 \mathrm{Fx}+0,3 \mathrm{Fy}$ & 12 & $\mathrm{U}=1,2 \mathrm{DL}+1,0 \mathrm{LL}+0,3 \mathrm{Fx}-1,0 \mathrm{Fy}$ \\
6 & $\mathrm{U}=1,2 \mathrm{DL}+1,0 \mathrm{LL}-1,0 \mathrm{Fx}-0,3 \mathrm{Fy}$ & 13 & $\mathrm{U}=1,2 \mathrm{DL}+1,0 \mathrm{LL}-0,3 \mathrm{Fx}+1,0 \mathrm{Fy}$ \\
7 & $\mathrm{U}=0,9 \mathrm{DL}+1,0 \mathrm{Fx}+0,3 \mathrm{Fy}$ & 14 & $\mathrm{U}=1,2 \mathrm{DL}+1,0 \mathrm{LL}-0,3 \mathrm{Fx}-1,0 \mathrm{Fy}$ \\
\hline
\end{tabular}

Dengan :

$\mathrm{U}=$ Kuat perlu, [kN atau kN.m]

$\mathrm{DL}=$ Beban mati, dapat berupa momen maupun gaya dalam akibat beban mati,

LL = Beban hidup, dapat berupa momen maupun gaya dalam akibat beban hidup,

$\mathrm{Fx}=$ Beban gempa arah X

Fy = Beban gempa arah Y 
Hasil analisis kolom dan balok dengan kombinasi pembebanan yang telah ditetapkan dapat dilihat pada Gambar 10 dibawah berikut. Tampak bahwa ada elemen balok yang mengalamai over strength $(\mathrm{O} / \mathrm{S})$ yang ditandai dengan warna merah, elemen struktur yang terjadi didapat dari kombinasi pembebanan 14 (Tabel 2) berupa faktor beban mati, beban hidup dan beban gempa.

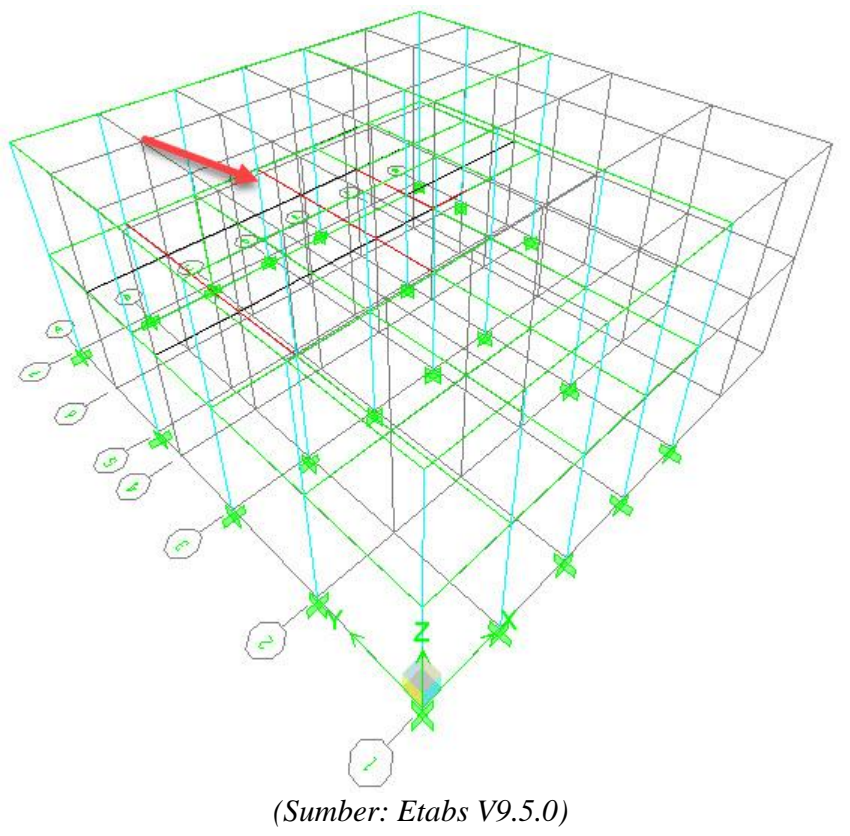

Gambar 11. Hasil Analisis Struktur

\section{Analisis Tahap 2}

Sama halnya dengan permodelan struktur eksisting, permodelan struktur eksisting dengan beban tambahan ruang kelas baru dilakukan dengan menggunakan Etabs V9.5.0 yang sama dengan analisis tahap 1 perbedaan terdapat pada penambahan lantai bangunan eksisting menjadi 3 lantai.

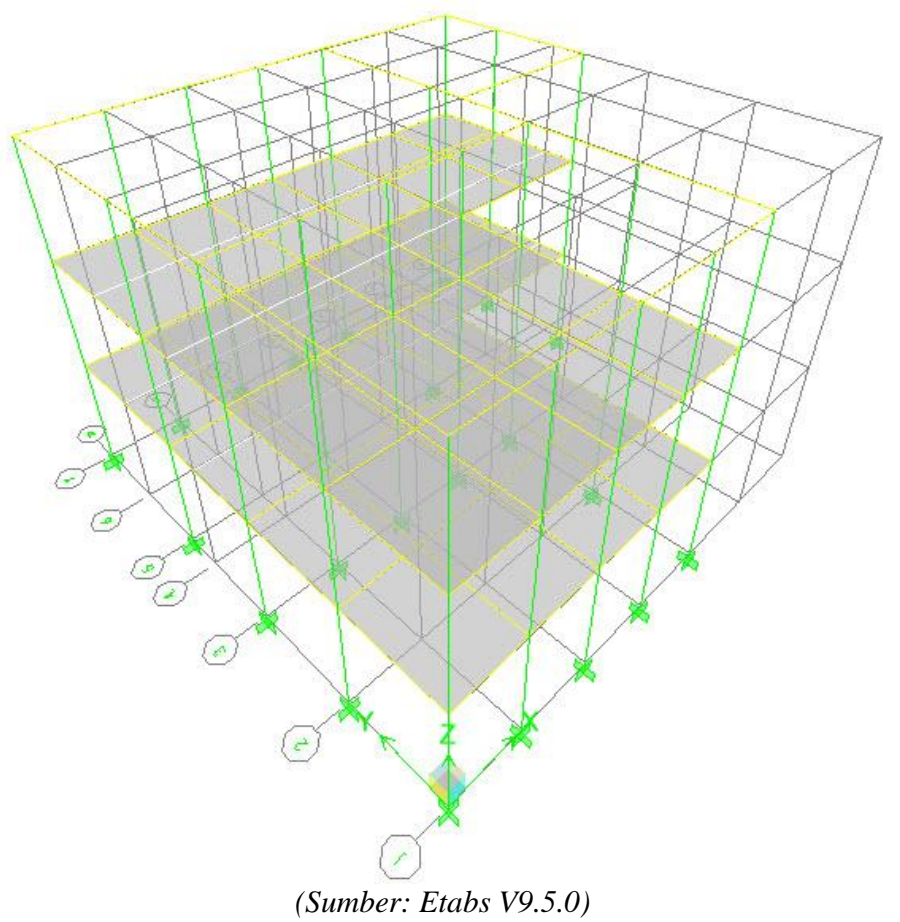

Gambar 12. Model Struktur Tambahan Ruang Kelas Baru 
Hasil analisis menunjukan bahwa ada 2 elemen struktur balok berukuran 20 x $30 \mathrm{~cm}$ dengan bentang panjang $7 \mathrm{~m}$ pada lantai 2 dan lantai 3 mengalamai over strength $(\mathrm{O} / \mathrm{S})$ terjadi pada kombinasi 14 (Tabel 2) ditunjukan pada Gambar 13.

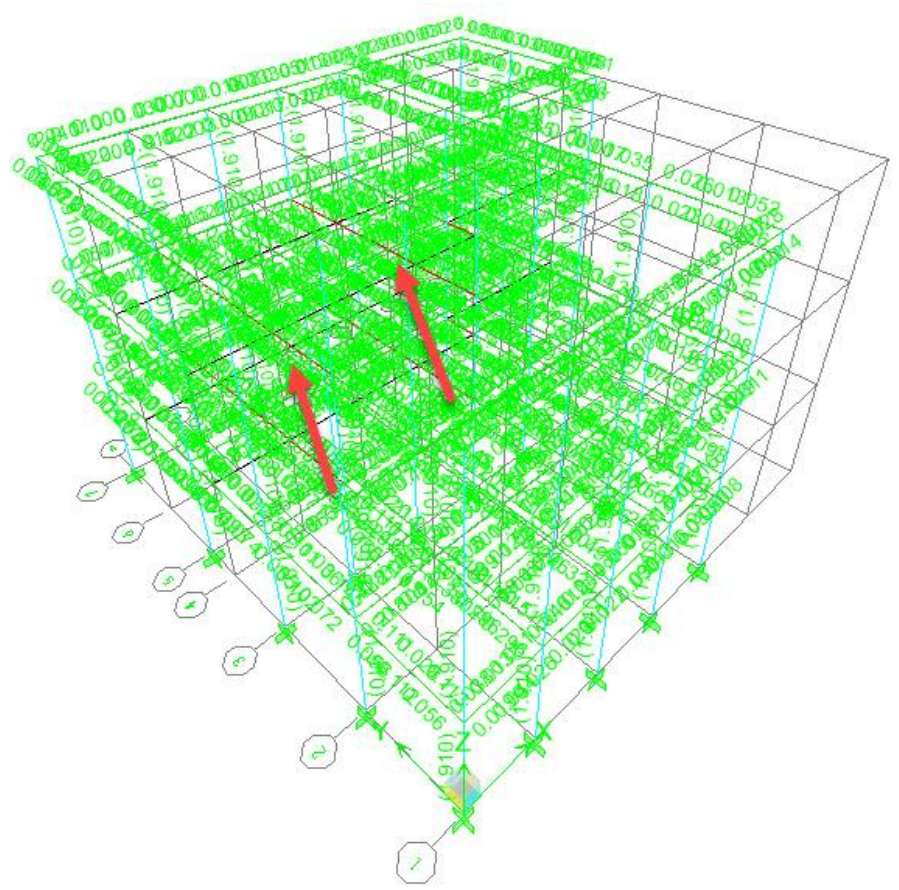

(Sumber : Etabs V 9.5.0)

Gambar 13. Elemen Struktur Mengalami Over Strength (Garis Merah)

\section{Analisis Tahap 3}

Setelah didapatkan hasil analisis tahap 1 dan 2, maka diperlukan penambahan perkuatan, untuk mengetahui metode perbaikan yang paling efektif dari segi kemanan, biaya, serta pelaksanaan pekerjaan, maka dilakukan 2 metode perbaikan yaitu, metode concrete jacketing dan perkuatan profil baja WF.

\section{Metode Concrete Jacketing}

Berdasarkan hasil analisis perhitungan perkuatan dengan balok eksisting 30 x 20 $\mathrm{cm}$ di ketahui mengalami over strength dan perlu di perkuat dengan perubahan dimensi menjadi $40 \times 30 \mathrm{~cm}$, tulangan longitudinal 5D-16, tulangan geser $\varnothing 8-100$, dan mutu beton 20,75 $\mathrm{MPa}$ dengan penambahan tulangan ditunjukan pada Gambar 14, dalam penambahan tulangan di beri tulangan pengekang antara tulangan longitudinal eksisting dengan tulangan longitudinal baru dengan cara pembobokan struktur balok eksisting kemudian di beri tulangan pengekang dan dilakukan pengelasan agar tulangan longitudinal baru menjadi kaku. 

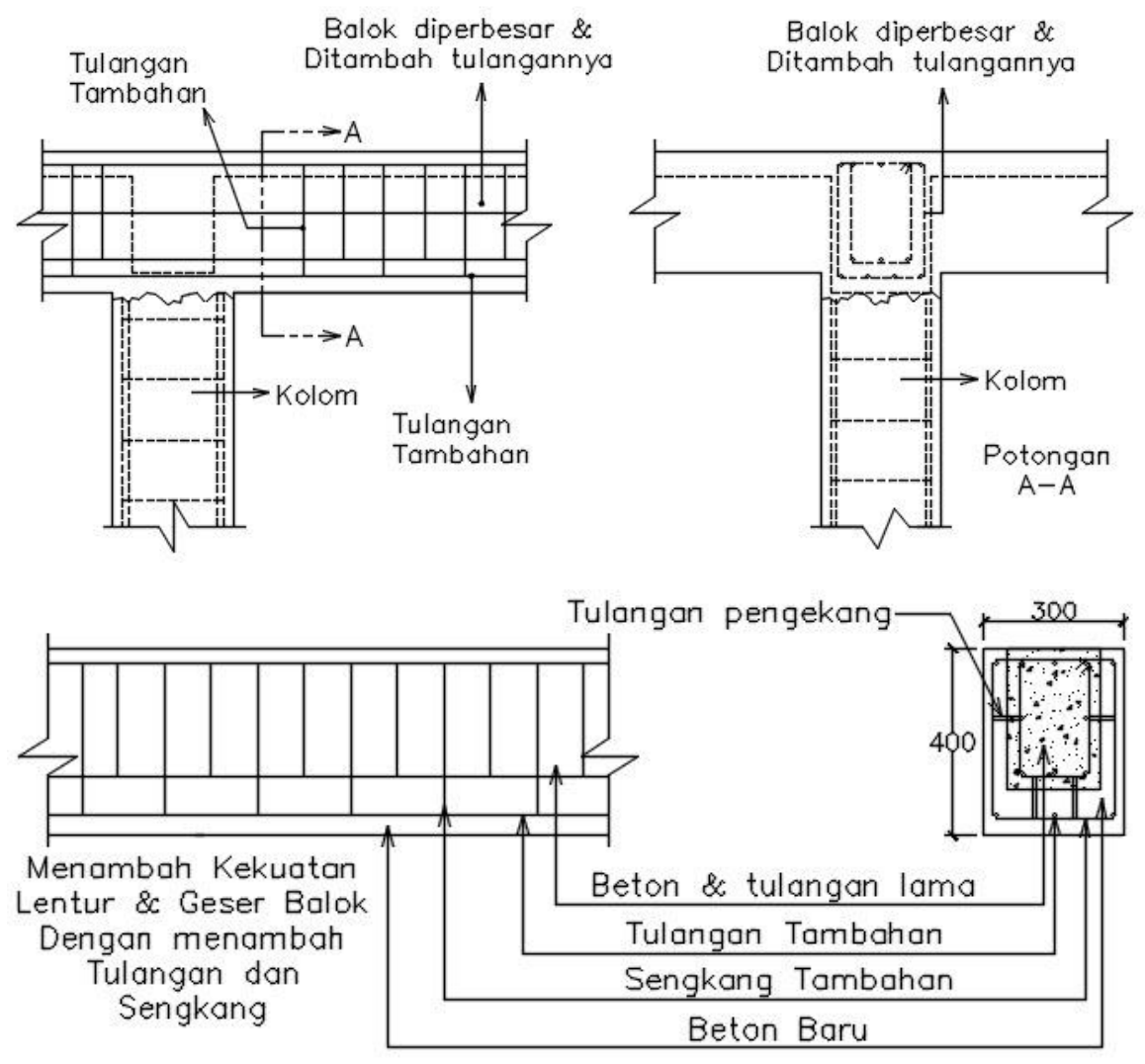

(Sumber : Gambar pribadi)

Gambar 14. Penambahan Dimensi Balok

Hasil permodelan perkuatan dilakukan dengan software Etabs V9.5.0 struktur dinyatakan aman dengan tidak adanya elemen struktur yang berwarna merah, ditunjukan pada Gambar 15.

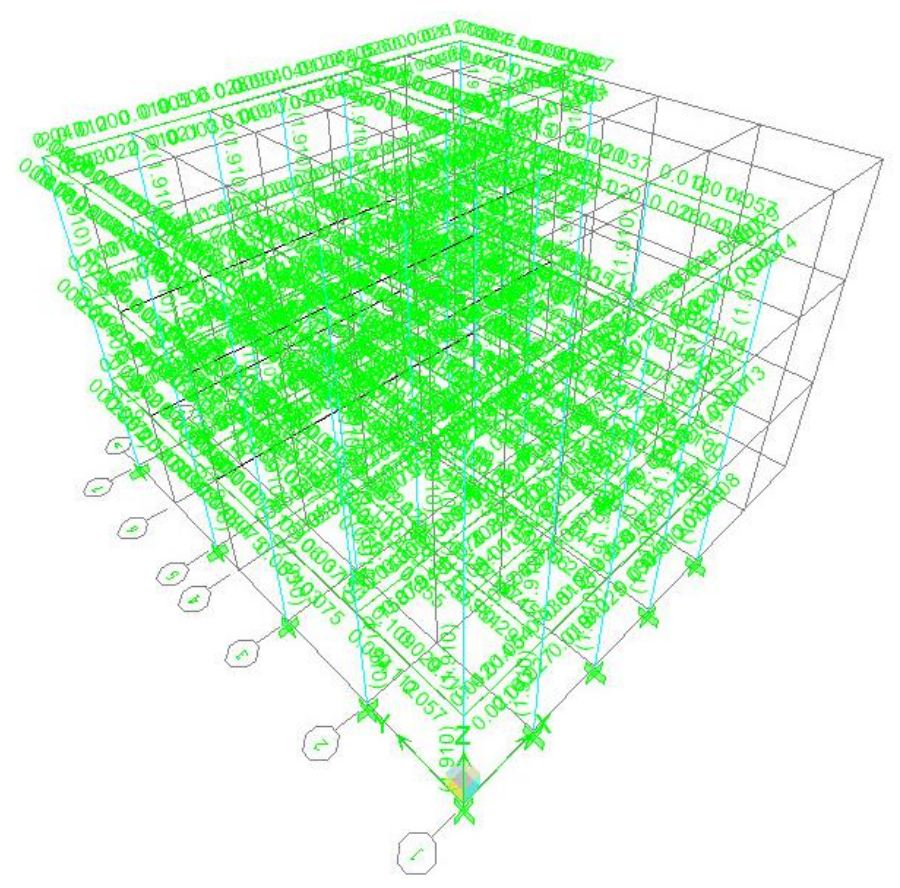

(Sumber : Etabs V 9.5.0)

Gambar 15. Hasil Analisis Perkuatan 


\section{Metode Perkuatan Dengan Menambahkan Profil Baja WF}

Berdasarkan hasil perencanaan perkuatan portal baja dengan metode perencanaan kondisi batas / limit states design (Load and Resistance Factor Design/LRFD) terhadap balok beton bertulang yang mengalami over strength, perkuatan menggunakan profil baja WF 200.200.8.12, dengan profil tersebut dinyatakan mampu menahan beban yang bekerja terhadap struktur. Sistem penyambungan antar baja menggunakan sistem pengelasan dan penyambungan antar baja dengan balok beton eksisting menggunakan angkur kemudian diberi chemical angkur.

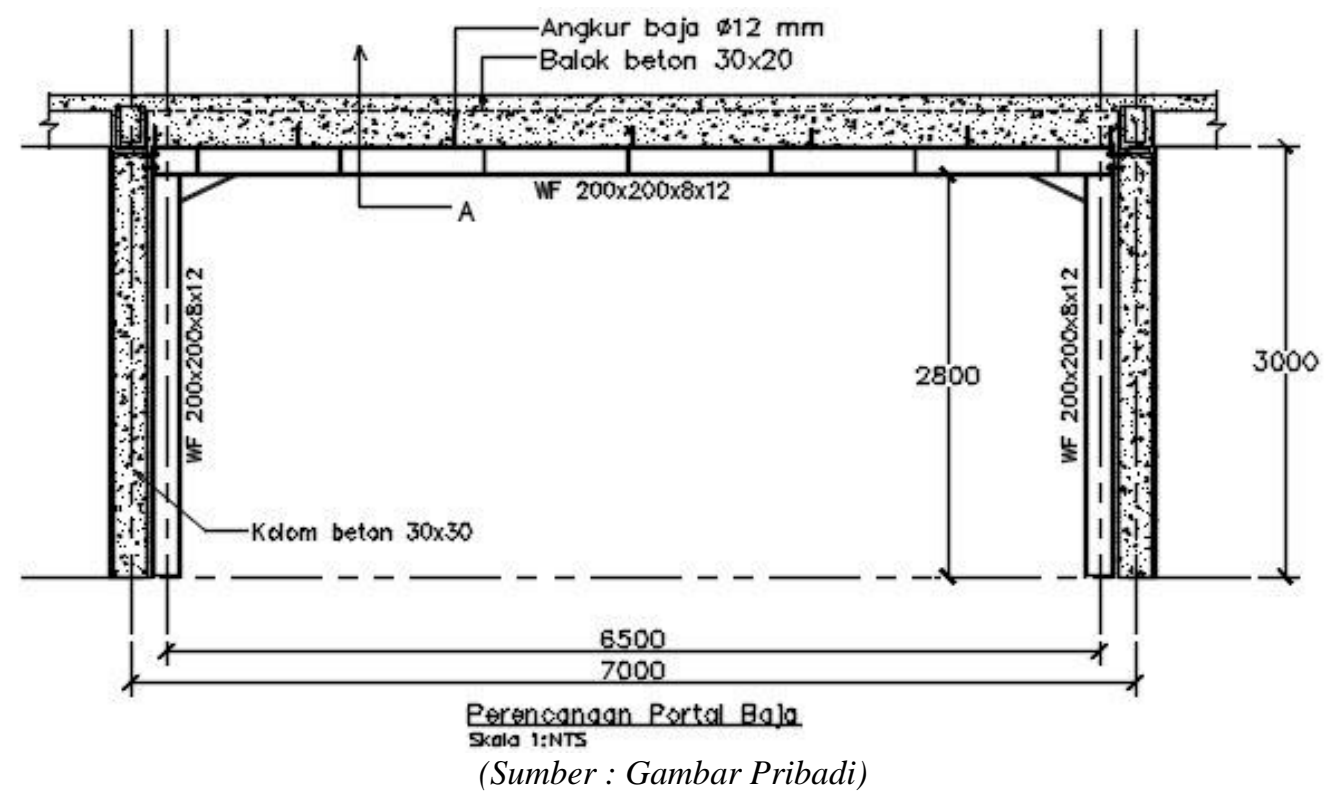

Gambar 16. Portal Baja Profil

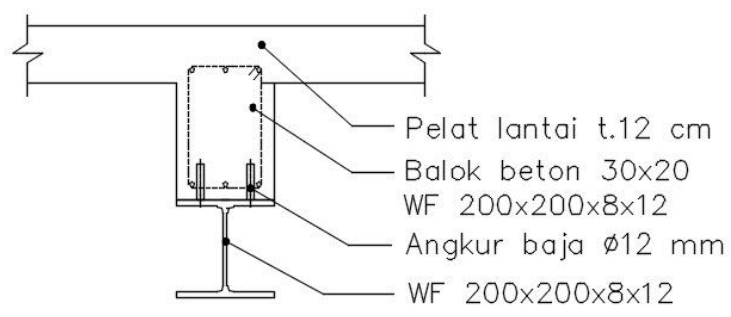

POT - A

(Sumber : Gambar Pribadi)

Gambar 17. Detail Potongan Portal

\section{Analisis Perhitungan Biaya}

Analisis perhitungan biaya dilakukan sebagai perbandingan antara perkuatan secara concrete jacketing dengan perkuatan profil, selisih perbandingan harga perkuatan profil baja lebih mahal $81 \%$ atau sebesar Rp 11.771.225,00 di bandingkan perkuatan concrete jacketing dalam perencanaan perkuatan struktur, analisis perhitunagan ditunjukan pada Tabel 3 dan 4. 
Tabel 3. Perhitungan Biaya Perkuatan Concrete Jacketing

\begin{tabular}{|c|c|c|c|c|c|c|c|c|c|}
\hline \multirow{3}{*}{$\begin{array}{c}\text { NO } \\
\mathbf{a} \\
\end{array}$} & \multirow{3}{*}{$\begin{array}{c}\text { URAIAN PEKERJAAN } \\
\text { b } \\
\end{array}$} & \multirow{3}{*}{$\begin{array}{c}\text { SAT } \\
\text { c } \\
\end{array}$} & \multirow{3}{*}{$\begin{array}{l}\text { VOLUME } \\
\text { d }\end{array}$} & \multicolumn{4}{|c|}{ HARGA SATUAN } & \multicolumn{2}{|r|}{ JUMLAH } \\
\hline & & & & \multicolumn{2}{|c|}{ UPAH(Rp) } & \multicolumn{2}{|c|}{ MATRIAL ( Rp) } & \multirow{2}{*}{\multicolumn{2}{|c|}{$=\mathbf{d} x(e+f)$}} \\
\hline & & & & & e & & $\mathbf{f}$ & & \\
\hline \multirow[t]{3}{*}{1} & Pekerjaan bobok balok eksisting & & & & & & & & \\
\hline & - bobok balok L-7 m @ 4 balok & ls & 1.00 & $\mathrm{Rp}$ & $400,000.00$ & \multirow{2}{*}{\multicolumn{2}{|c|}{ Sub Total }} & $\mathrm{Rp}$ & $400,000.00$ \\
\hline & & & & & & & & $\mathbf{R p}$ & $400,000.00$ \\
\hline \multirow[t]{5}{*}{2} & Pekerjaan Pembesian & & & & & & & & \\
\hline & - Besi D-13 & $\mathrm{kg}$ & 120.00 & $\mathrm{Rp}$ & $2,300.00$ & $\mathrm{Rp}$ & $7,700.00$ & $\mathrm{Rp}$ & $1,200,000.00$ \\
\hline & - Besi dia - 8 & $\mathrm{~kg}$ & 134.40 & $\mathrm{Rp}$ & $2,300.00$ & $\mathrm{Rp}$ & $7,700.00$ & $\mathrm{Rp}$ & $1,344,000.00$ \\
\hline & - Chemical angkur hilty & tube & 2.00 & & & $\mathrm{Rp}$ & $345,000.00$ & $\mathrm{Rp}$ & $690,000.00$ \\
\hline & & & & & & \multicolumn{2}{|c|}{ Sub Total } & $\mathbf{R p}$ & $3,234,000.00$ \\
\hline \multirow[t]{5}{*}{3} & Pekerjaan Bekisting & $\mathrm{m} 2$ & 27.70 & $\mathrm{Rp}$ & $35,000.00$ & & & $\mathrm{Rp}$ & $969,500.00$ \\
\hline & - Triplek $9 \mathrm{~mm}$ & $\mathrm{lbr}$ & 10.00 & & & $\mathrm{Rp}$ & $124,000.00$ & $\mathrm{Rp}$ & $1,240,000.00$ \\
\hline & - Kaso 4 x 6 & btg & 42.00 & & & $\mathrm{Rp}$ & $28,000.00$ & $\mathrm{Rp}$ & $1,176,000.00$ \\
\hline & - Paku $7 \mathrm{~cm}$ & $\mathrm{~kg}$ & 3.00 & & & $\mathrm{Rp}$ & $17,000.00$ & $\mathrm{Rp}$ & $51,000.00$ \\
\hline & & & & & & \multicolumn{2}{|c|}{ Sub Total } & $\mathbf{R p}$ & $3,436,500.00$ \\
\hline \multirow[t]{3}{*}{4} & Pekerjaan Pengecoran & $\mathrm{m} 3$ & 2.45 & $\mathrm{Rp}$ & 600,000 & \multirow{3}{*}{\multicolumn{2}{|c|}{ Sub Total }} & $\mathrm{Rp}$ & $1,470,000.00$ \\
\hline & - Sement instan K250 ex.Drymix & zak & 105.35 & & & & & $\mathrm{Rp}$ & $5,583,550.00$ \\
\hline & & & & & & & & $\mathbf{R p}$ & $7,053,550.00$ \\
\hline \multirow[t]{4}{*}{5} & Pekerjaan finishing & & & & & & & & \\
\hline & - Kompound & $\mathrm{m} 2$ & 26.6 & $\mathrm{Rp}$ & $10,000.00$ & $\mathrm{Rp}$ & $5,000.00$ & $\mathrm{Rp}$ & $399,000.00$ \\
\hline & & & & & & \multicolumn{2}{|c|}{ Sub Total } & $\mathbf{R p}$ & $399,000.00$ \\
\hline & & \multicolumn{4}{|c|}{ TOTAL BIAYA } & & & \multicolumn{2}{|c|}{ Rp 14,523,050.00 } \\
\hline
\end{tabular}

Tabel 4. Perhitungan Biaya Perkuatan Profil Baja WF 200.200.8.12

\begin{tabular}{|c|c|c|c|c|c|c|c|c|c|}
\hline \multirow{3}{*}{$\begin{array}{r}\text { NO } \\
\mathbf{a} \\
\end{array}$} & \multirow{3}{*}{$\begin{array}{c}\text { URAIAN PEKERJAAN } \\
\text { b }\end{array}$} & \multirow{3}{*}{$\begin{array}{l}\text { SAT } \\
\text { c }\end{array}$} & \multirow{3}{*}{$\begin{array}{c}\text { VOLUME } \\
\text { d }\end{array}$} & \multicolumn{4}{|c|}{ HARGA SATUAN } & \multicolumn{2}{|r|}{ JUMLAH } \\
\hline & & & & \multirow{2}{*}{\multicolumn{2}{|c|}{$\begin{array}{c}\text { UPAH(Rp) } \\
\text { e }\end{array}$}} & \multicolumn{2}{|c|}{ MATRIAL ( Rp) } & \multirow{2}{*}{\multicolumn{2}{|c|}{$=d x(e+f)$}} \\
\hline & & & & & & & f & & \\
\hline \multirow[t]{7}{*}{1} & Pekerjaan Struktur Portal Baja lant & & & & & & & & \\
\hline & WF200.200.8.12 & $\mathrm{kg}$ & 613.77 & $\mathrm{Rp}$ & $6,000.00$ & $\mathrm{Rp}$ & $12,000.00$ & $\mathrm{Rp}$ & $11,047,860.00$ \\
\hline & base palte $300 \times 300 \times 10$ & $\mathrm{~kg}$ & 14.13 & & & $\mathrm{Rp}$ & $9,500.00$ & $\mathrm{Rp}$ & $134,235.00$ \\
\hline & Plate stifner 200x100x8 & $\mathrm{kg}$ & 12.56 & & & $\mathrm{Rp}$ & $9,500.00$ & $\mathrm{Rp}$ & $119,320.00$ \\
\hline & Angkur & pes & 12.00 & $\mathrm{Rp}$ & $20,000.00$ & $\mathrm{Rp}$ & $30,000.00$ & $\mathrm{Rp}$ & $600,000.00$ \\
\hline & Chemical angkur hilty & tube & 1.00 & & & $\mathrm{Rp}$ & $345,000.00$ & $\mathrm{Rp}$ & $345,000.00$ \\
\hline & & & & & & & Sub Total & $\mathbf{R p}$ & $11,047,860.00$ \\
\hline \multirow[t]{7}{*}{2} & Pekerjaan Struktur Portal Baja lant & & & & & & & & \\
\hline & WF200.200.8.12 & $\mathrm{kg}$ & 613.77 & $\mathrm{Rp}$ & $6,000.00$ & $\mathrm{Rp}$ & $12,000.00$ & $\mathrm{Rp}$ & $11,047,860.00$ \\
\hline & base palte $300 \times 300 \times 10$ & $\mathrm{~kg}$ & 14.13 & & & $\mathrm{Rp}$ & $9,500.00$ & $\mathrm{Rp}$ & $134,235.00$ \\
\hline & Plate stifner 200x100x8 & $\mathrm{kg}$ & 12.56 & & & $\mathrm{Rp}$ & $9,500.00$ & $\mathrm{Rp}$ & $119,320.00$ \\
\hline & Angkur & pes & 12.00 & $\mathrm{Rp}$ & $20,000.00$ & $\mathrm{Rp}$ & $35,000.00$ & $\mathrm{Rp}$ & $660,000.00$ \\
\hline & Chemical angkur hilty & tube & 1.00 & & & $\mathrm{Rp}$ & $345,000.00$ & $\mathrm{Rp}$ & $345,000.00$ \\
\hline & & & & & & & Sub Total & $\mathbf{R p}$ & $12,306,415.00$ \\
\hline \multirow[t]{7}{*}{3} & Pekerjaan Struktur Pondasi (2 ttk) & $\mathrm{m} 3$ & 0.50 & $\mathrm{Rp}$ & $600,000.00$ & & & $\mathrm{Rp}$ & $300,000.00$ \\
\hline & Galian & $\mathrm{m} 3$ & 0.50 & $\mathrm{Rp}$ & $90,000.00$ & & & $\mathrm{Rp}$ & $45,000.00$ \\
\hline & Pembesian & $\mathrm{kg}$ & 51.00 & $\mathrm{Rp}$ & $2,300.00$ & $\mathrm{Rp}$ & $7,700.00$ & $\mathrm{Rp}$ & $510,000.00$ \\
\hline & - Sement instan K250 ex.Drymix & zak & 25.00 & & & $\mathrm{Rp}$ & $53,000.00$ & $\mathrm{Rp}$ & $1,325,000.00$ \\
\hline & Angkur dia.16 L-300 & pes & 8.00 & $\mathrm{Rp}$ & $35,000.00$ & $\mathrm{Rp}$ & $60,000.00$ & $\mathrm{Rp}$ & $760,000.00$ \\
\hline & & & & & & & Sub Total & $\mathbf{R p}$ & $2,940,000.00$ \\
\hline & & & & & TOTA & L 1 . & AYA & $\mathbf{R p}$ & $26,294,275.00$ \\
\hline
\end{tabular}




\section{KESIMPULAN}

Dari hasil analisis yang dilakukan menggunakan Software Etabs V9.5.0 di dapatkan kesimpulan sebagai berikut :

1. Struktur bangunan eksisting tidak dapat menahan beban akibat penambahan ruang kelas baru dilihat dari elemen balok struktur yang mengalami over strength $(\mathrm{O} / \mathrm{S})$ ditandai dengan warna merah pada elemen struktur balok.

2. Analisis perkuatan dilakukan dengan 2 metode, diantaranya :

a. Perkuatan secara concrete jacketing, penambahan dimensi elemen balok struktur dari ukuran $30 \times 20 \mathrm{~cm}$ menjadi $35 \times 25 \mathrm{~cm}$ dengan tulangan longitudinal 5D16, tulangan geser Ø8-100, dan mutu beton 20,75 Mpa

b. Perkuatan secara penambahan profil baja WF 200.200.8.12 sebagai penopang elemen struktur balok.

\section{DAFTAR PUSTAKA}

Asroni, Ali. (2010). Balok dan Plat Beton Bertulang. Graha Ilmu. Yogyakarta.

Asroni, Ali. (2010a). Kolom, Fondasi dan Balok "T" Beton Bertulang. Graha Ilmu. Yogyakarta.

Lutfi, M. \& Subtoni. (2017). "Kajian struktur bangunan akibat penurunan mutu beton pada kolom terpasang (Studi Kasus: SDN 01 Cikaret Kabupaten Bogor)". Jurnal ASTONJADRO - Aspal, Beton, Baja, dan Hidro. Vol. 6, No 1, Desember 2017, Hal: 115129.

Aswin, M. (2010). "Nilai over strength factor pada balok beton bertulang yang menggunakan serat bendrat dan tulangan baja yang sudah mengalami pembengkokan (Kajian analitis dan eksperimental)". Jurnal Rekayasa Struktur \& Infrastruktur, Vol. 4, No.1, Hal: 44-54.

Pamungkas, A. \& Harianty, E. (2009). Gedung Beton Bertulang Tahan Gempa. CV. Putra Media Nusantara. Surabaya.

Setiawan, Agus. (2013). Perencanaan Struktur Baja dengn Metode LRFD. Erlangga. Jakarta.

SNI 03-1726-2012. SNI 03-1726-2012 tentang Tata Cara Perencanaan Ketahanan Gempa Untuk Bangunan Gedung UU No. 28 Tahun 2002.

UU 28/02. Undang-Undang Nomor 28 Tahun 2002 tentang Bangunan Gedung.

SNI 1729:2015. SNI 1729:2015 tentang Spesifikasi untuk Bangunan Gedung Baja Struktural.

Suprayitno, H. \& Soemitro, RAA. (2018). "Preliminary Reflexion on Basic Principle of Infrastructure Asset Management". Jurnal Manajemen Aset Infrastruktur \& Fasilitas, Vol. 2, No. 1, Maret 2018, Hal: 1-10.

Tjokrodimulyo, K. (2007). Teknologi Beton. Buku Ajar. Jurusan Teknik Sipil, Fakultas Teknik, Universitas Gajah Mada. Yogyakarta. 
(e)ISSN 2615-1847 (p)ISSN 2615-1839

Jurnal Manajemen Aset Infrastruktur \& Fasilitas - Vol. 4, No. 2, April 2020 